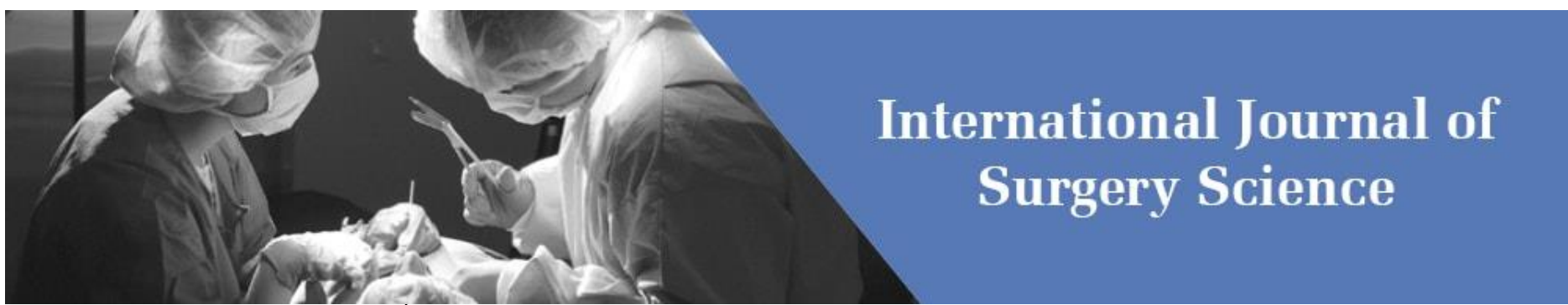

E-ISSN: 2616-3470

P-ISSN: 2616-3462

(C) Surgery Science

www.surgeryscience.com

2020; 4(1): 364-368

Received: 13-11-2019

Accepted: 15-12-2019

Dr. Himanshu Raj

Senior Resident,

Aarupadai Veedu Medical College,

Pondicherry, India

Dr. Annamalai Azhagar

Assistant Professor,

Aarupadai Veedu Medical College,

Pondicherry, India

Corresponding Author:

Dr. Annamalai Azhagar

Assistant Professor,

Aarupadai Veedu Medical College,

Pondicherry, India

\section{Validity of diagnostic laparoscopy in diagnosis of acute appendicitis}

\section{Dr. Himanshu Raj and Dr. Annamalai Azhagar}

DOI: https://doi.org/10.33545/surgery.2020.v4.i1g.364

\section{Abstract}

Background: Acute appendicitis is the most common surgical emergency encountered in general population, especially among the pediatric age group. Till date, there are no definitive diagnostic tools available for deriving precise diagnosis. This study was carried out to evaluate the validity of diagnostic laparoscopy in detecting acute appendicitis.

Methods: This cross sectional study was carried out among 130 patients who were clinically diagnosed with acute appendicitis. Diagnostic laparoscopy was carried out to evaluate the appendix and was documented. In necessary situations, the procedure was converted into appendectomy. The excised specimen was sent for histopathological examination.

Results: On comparing the validity of clinical features with respect to diagnostic laparoscopy, highest sensitivity was observed with RIF tenderness $(100 \%)$ followed by anorexia (78.8\%) and nausea/ vomiting (74.7\%). However, specificity was found to be highest for migratory pain $(83.9 \%)$. The sensitivity of the diagnostic laparoscopy when compared to the gold standard histopathological finding was $97.1 \%$.

Conclusion: Since diagnostic laparoscopy is a non invasive tool, it may be used as a standard protocol for immediate management of acute appendicitis, and also be used as a potent tool for differential diagnosis among women of the reproductive age.

Keywords: Acute appendicitis, laparoscopy, right ilia fossa tenderness, migratory pain

\section{Introduction}

Appendicitis is the most common acute surgical emergency among the general population, especially in the pediatric age group. Approximately seven percent of population will have appendicitis in their lifetime. The peak age of incidence of appendicitis is between the ages of 10 and 30years. The clinical diagnosis of acute appendicitis is unreliable despite numerous attempts to improve diagnostic accuracy. This often results in negative exploration. Historically diagnosis of appendicitis has been predominantly clinical, aided with radiological methods like Ultrasound/ Computerized Tomography (CT) or Magnetic Resonance Imaging (MRI) scans. In most cases, invasive procedures like open laparotomy has been resorted to for diagnosis and management. Both ultrasonography and computed Tomography (CT) have shown to be of considerable value in obtaining the diagnosis of appendicitis. However, ultrasound appears to be highly observer dependent and is not useful in ruling out appendicitis in the general population. CT-scan, although helps in diagnosis, has limitations with respect to application in lower socioeconomic sections and also has considerable radiation exposure. Routine application of these new diagnostic tools in patients with suspected appendicitis might cause unnecessary delay, costs and patient discomfort.

Exploratory laparoscopy is being considered as a semi-invasive procedure, in comparison with non-invasive radiological methods and invasive procedures like open laparotomy. According to the literature, mostly in retrospective studies, laparoscopy might reduce the frequencies of unnecessary appendectomies in $20-30 \%$. Moreover, studies have documented an accuracy of diagnosis upto 95- 99\%, with a sensitivity of $92 \%{ }^{[1]}$. Diagnostic laparoscopy is a safe procedure that reduced the appendix sana rate without increasing the total number of operations. Moreover, the diagnostic procedure can be converted into a therapeutic one, upon confirming the diagnosis of appendicitis, thereby minimizing operational costs and discomforts.

Diagnostic outcomes favored the laparoscopic approach in that both the negative appendectomies rate and "the frequency of an unestablished diagnosis" were reduced, most 
significantly in women in their reproductive years ${ }^{[1]}$. Larger application of diagnostic laparoscopy in patients suspected of acute appendicitis will reduce significantly the rate of diagnostic mistakes, complications and unwarranted appendectomies ${ }^{[2]}$. The diagnostic accuracy in patients with suspected acute appendicitis varies from $60 \%$ to $90 \%$ depending on age and gender. Substantial education effort is needed to introduce diagnostic laparoscopy on a 24 -h-a-day basis. Diagnostic laparoscopy has a high rate of accuracy, short operating time, and low associated morbidity, and prevents unnecessary laprotomy. It is possible to leave a macroscopically normal appearing appendix in place ${ }^{[3]}$.

\section{Objectives}

This study was carried out to evaluate the diagnostic accuracy of laparoscopy and compare it with clinical examination findings for the diagnosis of acute appendicitis.

\section{Methods}

\section{Study setting and participants}

This study was carried out as a cross sectional study in the Department of General Surgery of our tertiary teaching institution for a period of 23 months between February 2016 and December 2017.

\section{Selection criteria}

All the patients between 13-50 years clinically diagnosed with acute appendicitis and are not contraindicated for laparoscopy were taken up for the study.

\section{Sample size and sampling technique}

Based on the previous trends of diagnostic accuracy in our hospital (90\% in 2015), the same was taken for sample size calculation. At $95 \%$ level of significance and $0.05 \%$ absolute precision and $7 \%$ margin of error, the sample size was calculated as 138 and rounded off to 140 .

\section{Ethical approval and informed consent}

Approval was obtained from the Institutional Ethics Committee prior to the commencement of the study. Each participant was explained in detail and informed consent was obtained prior to the data collection. In case of children and minors, informed consent was obtained from the parents/guardian after explaining about the study.

\section{Procedure}

The suspicion of acute appendicitis was made, based on the presence of classical clinical parameters including migratory pain, anorexia, nausea and vomiting, tenderness in the right iliac fossa, rebound tenderness, fever and laboratory confirmation of elevated white blood cell counts. Under general anesthesia, a Diagnostic laparoscopy was performed within 24 hoursof presentation. If during laparoscopy inflammation of the appendix was confirmed, criteria being turgidity and hyperemia of the appendix or if the appendix could not be visualized because of pus, exudate, or adhesions, the procedure was converted into appendectomy either through laparoscopy or open approach. The excised sample was sent for histopathologic correlation. If no signs of appendicular inflammation were seen, the appendix was left in place, even if no other causative pathology was diagnosed. If an appendicular mass was found, the appendix was left in place and further clinical management was done. Those participants who did not undergo appendectomy were followed up for at least 6 weeks postoperatively for physical examination and laboratory investigations to rule out the diagnosis of recurrent appendicitis.

\section{Data collection and analysis}

A structured proforma was used to obtain information regarding demographic characteristics, laboratory parameters, clinical signs and symptoms and intra operative parameters. Data was entered and analyzed using EPI Info ver. 7 software. Descriptive data was represented as mean \pm SD for numeric variables, percentages and proportions for categorical variables. Diagnostic accuracy was done using sensitivity and specificity tests.

\section{Results}

This study was carried out among 130 participants who presented with clinical findings suggestive of acute appendicitis. Majority of the participants belonged to the age group of 20-30 years and were males $(50.8 \%)$. (Table 1$)$

All the participants in this study presented with Right Iliac Fossa (RIF) tenderness $(100 \%)$ while about $76.2 \%$ presented with anorexia and $73.8 \%$ presented with nausea/ vomiting. Ultrasound findings showed presence of acute appendicitis in $58.5 \%$ of the participants. (Table 2)

The diagnostic laparoscopy showed inflamed appendix in $66.2 \%$ of the participants, appendicular mass in $2.3 \%$ and appendix was not visualized in $10 \%$ of the participants. Among the $10 \%$ who had other diagnosis, pelvic inflammatory disease was the most common presentation (30.8\%). (Table 3)

The diagnostic laparoscopy was converted to laparoscopic appendectomy in $66.2 \%$ of the participants, while open appendectomy was performed in $10 \%$. (Table 4) On histopathological examination of excised specimen, acute appendicitis was confirmed in $77 \%$ of the participants, while chronic appendicitis was present in $0.8 \%$ of the participants. (Table 5)

An evaluation was done to compare the laparoscopic findings with respect to other diagnostic features. It was observed that among 85 participants who presented with inflamed appendix, $81.4 \%$ had nausea/ vomiting and $73.3 \%$ had positive ultrasound findings. Among the 13 participants in whom appendix was not visualized, $30.8 \%$ had nausea/ vomiting while $38.5 \%$ had positive ultrasound findings. The observed difference was statistically significant for both clinical features (nausea/vomiting) and ultrasound findings ( $\mathrm{p}<0.0001)$. (Table 6) On comparing the validity of clinical features with respect to diagnostic laparoscopy, highest sensitivity was observed with RIF tenderness (100\%) followed by anorexia (78.8\%) and nausea/ vomiting $(74.7 \%)$. However, specificity was found to be highest for migratory pain $(83.9 \%)$. (Table 7 )

The sensitivity of the diagnostic laparoscopy when compared to the gold standard histopathological finding was $97.1 \%$. (Table 8) As there were no true negative in the histopathological findings, it can be inferred that the specificity is equal to $1(100 \%)$. 
Table 1: Background characteristics

\begin{tabular}{|c|c|c|c|}
\hline S. No & Characteristics & Frequency (N=130) & Percentage (\%) \\
\hline $\mathbf{1}$ & \multicolumn{3}{|c|}{ Age (in years) } \\
\hline & $<20$ & 29 & 22.30 \\
\hline & $20-30$ & 48 & 36.90 \\
\hline & $31-40$ & 36 & 27.70 \\
\hline & $>40$ & 17 & 13.10 \\
\hline $\mathbf{2}$ & Male & 66 & 50.80 \\
\hline & Female & 64 & 49.20 \\
\hline
\end{tabular}

Table 2: Clinical symptoms of the study participants

\begin{tabular}{|c|c|c|c|}
\hline S. No & Characteristics & Frequency (N=130) & Percentage (\%) \\
\hline $\mathbf{1}$ & Clinical symptoms & 31.5 \\
\hline & Anratory pain & 41 & 76.2 \\
\hline & Nausea/ vomiting & 99 & 73.8 \\
\hline & RIF tenderness & 96 & 100 \\
\hline & Rebound tenderness & 130 & 60.8 \\
\hline & Fever & 79 & 43.8 \\
\hline $\mathbf{2}$ & \multicolumn{2}{|c|}{ Ultrasound findings } & 58.5 \\
\hline & Acute Appendicitis & 76 & 41.5 \\
\hline
\end{tabular}

Table 3: Laparoscopic findings of the study participants

\begin{tabular}{|c|c|c|c|}
\hline S. No & Laparoscopic Findings & Frequency & Percentage \\
\hline 1 & Appendix Inflamed & 86 & 66.2 \\
\hline 2 & Appendicular Mass & 3 & 2.3 \\
\hline 3 & Appendix not visualized & 13 & 10.0 \\
\hline 4 & Appendix Not Inflamed & 15 & 11.5 \\
\hline 5 & Appendix Not Inflamed/Other Diagnosis & 13 & 10 \\
\hline A & Ovarian Cyst. & 2 & $15.4 \%$ \\
\hline B & Adnexal torsion & 1 & $7.7 \%$ \\
\hline C & Adhesions & 1 & $7.7 \%$ \\
\hline D & Pelvic Inhammatory disease & 4 & $30.8 \%$ \\
\hline E & Salpingitis & 2 & $15.4 \%$ \\
\hline F & Corpus luteal Hemorrhage & 1 & $7.7 \%$ \\
\hline G & Hematosalpinx & 2 & $15.4 \%$ \\
\hline
\end{tabular}

Table 4: Management of acute appendicitis

\begin{tabular}{|c|c|c|c|}
\hline S. No & Treatment & Frequency & Percentage \\
\hline 1 & Laparoscopic Appendectomy & 86 & $66.20 \%$ \\
\hline 2 & Open Appendectomy & 13 & $10 \%$ \\
\hline 3 & Appendectomy Deferred & 31 & $23.80 \%$ \\
\hline 4 & Interval appendectomy & 3 & 2.3 \\
\hline
\end{tabular}

Table 5: Histopathological findings

\begin{tabular}{|c|c|c|c|}
\hline S. No & Histopathology & Frequency N = 130 & Percentage (\%) \\
\hline 1 & Acute Appendicitis & 101 & $77.70 \%$ \\
\hline 2 & Chronic Appendicitis & 1 & $0.80 \%$ \\
\hline 3 & Not done & 28 & $21.50 \%$ \\
\hline
\end{tabular}

Table 6: Association between laparoscopic findings and clinical features

\begin{tabular}{|c|c|c|c|c|}
\hline \multirow{2}{*}{ S. No } & \multirow{2}{*}{ Laparoscopic Findings } & \multirow{2}{*}{ Total Numbers } & \multicolumn{2}{c|}{ Other diagnostic features } \\
\cline { 3 - 4 } & & & Nausea/ Vomiting & Ultrasound findings \\
\hline 1 & Appendix Inflamed & 36 & $70(81.4 \%)$ & $63(73.3 \%)$ \\
\hline 2 & Appendicular Mass & 13 & $2(66.7 \%)$ & $0(0 \%)$ \\
\hline 3 & Appendix not visualized & 15 & $13(30.8 \%)$ & $5(38.5 \%)$ \\
\hline 4 & Appendix Not Inflamed & 13 & $7(53.8 \%)$ & $6(40 \%)$ \\
\hline 5 & Appendix Not Inflamed/Other Diagnosis & & 19.1 & $2(15.4 \%)$ \\
\hline \multicolumn{3}{|c|}{ Chi square } & $<0.0001 *$ & 26.2 \\
\hline
\end{tabular}


Table 7: Validity of diagnostic laparoscopy in comparison with clinical features

\begin{tabular}{|c|c|c|c|c|c|}
\hline Clinical Symptoms Presence & Total Number & Appendectomy done & Appendectomy not done & Sensitivity & Specificity \\
\hline Migratory pain & 41 & 36 & 5 & $36.4 \%$ & $83.9 \%$ \\
\hline Anorexia & 99 & 78 & 21 & $78.8 \%$ & $32.3 \%$ \\
\hline Nausea/Vomiting & 96 & 74 & 22 & $74.7 \%$ & $29 \%$ \\
\hline RIF tenderness & 130 & 99 & 31 & $100 \%$ & $0 \%$ \\
\hline Rebound tenderness & 79 & 65 & 14 & $65.7 \%$ & $54.8 \%$ \\
\hline Fever & 57 & 43 & 14 & $43.4 \%$ & $54.8 \%$ \\
\hline
\end{tabular}

Table 8: Validity of diagnostic laparoscopy in comparison with histopathological examination

\begin{tabular}{|c|c|c|}
\hline \multirow{2}{*}{ Diagnostic Laparoscopy } & \multicolumn{2}{|c|}{ Histopathological findings } \\
\cline { 2 - 3 } & Positive & Negative \\
\hline Positive & $99(97.1 \%)$ & $0(0 \%)$ \\
\hline Negative & $3(2.9 \%)$ & $0(0 \%)$ \\
\hline
\end{tabular}

\section{Discussion}

Acute appendicitis is one of the most common surgical emergency. In the 21st century, the incidence of appendicitis or appendectomy is high in newly industrialized countries in Asia (South Korea pooled: 206), the Middle East (Turkey pooled: 160), and Southern America (Chile: 202) per 100,000 personyears ${ }^{[4]}$. Till recent times, majority of the interventions for appendicitis management has resulted in a high negative appendectomy (NA) rate. A low NA rate is a measure of quality of care given at any institution.

A total of 130 cases with a suspicion of acute appendicitis were included in this study over a period of 2 years. Each case was evaluated clinically and included in the study only if the clinical diagnosis was acute appendicitis. No mortality was encountered during the entire study period. The range of age in the study was between 13 and 50 yrs. with peak age interval 10-30 yrs. accounting for $59.2 \%$. Review of other studies elsewhere showed similar incidences for age range, peak and sex distributions ${ }^{[5,6]}$.

Diagnostic laparoscopy was done for all the 130 patients included in our study. The Laparoscopic Findings showed that the majority of Patients had Appendix Inflamed 86 (66.2\%). Appendicular Mass was seen in 3(2.3\%) of patients. Appendix not visualized in $13(10 \%)$ of patients and Appendix Not Inflamed in $15(11.5 \%)$ of Patients. Out of 130 patients in our study, all of them presented with RIF tenderness, followed by anorexia, and nausea/ vomiting. In our study it is $74.7 \%$ and $29 \%$. The $p$ value $<0.001$ (which is lesser than 0.05 ) shows that there is a significant relation between the Laparoscopic Findings and the presence of Nausea/Vomiting.

In ultrasound examination, appendicitis is recognized as a noncompressible blind-ended tubular structure, with an enlarged diameter of more than $6 \mathrm{~mm}{ }^{[7]}$. There were 17 articles retrieved concerning the use of US in patients with suspected appendicitis [8-10] Of these, only 8 studies clearly described sensitivity rates (varying from 0.755 to 0.90 ), specificity rates (varying from 0.73 to 1 ) and accuracy rates (varying from 0.76 to 0.96 ). The relatively low sensitivity rates of Ultrasoundindicatesits low validity. Out of 86 patients who had Appendix Inflamed, 73.3\% of them had Acute Appendicitis according to the result of Ultrasonography $(\mathrm{p}<0.001)$

In seven well-documented prospective studies specificity rates ranged from 0.733 to 1 , achieving negative appendectomy rates from 0 to $13 \% .^{(101-107)}$ No patient developed signs of appendicitis in the direct post-operative period: the sensitivity was therefore $1^{[11-17]}$. There was also no increased risk for future appendicitis during long-term follow up. Thus, normal appearing appendices should not be removed. Although macroscopically normal appearing appendices might show inflammatory responses, these findings are apparently of no clinical importance ${ }^{[18]}$ Complication rates varied from 0 to $2 \%$ and include a pulmonary embolism, ileus, wound infections, lung complications and bleedings from trocar ports ${ }^{[19]}$. No injuries due to introduction of the Veress needle were reported. Because recent meta-analyses show advantages of laparoscopic appendectomy over open appendectomyless wound infections and minimal reduction in hospital stay, ideally, all patients with suspected appendicitis will undergo routinely diagnostic laparoscopy, followed by laparoscopic appendectomy if necessary [20-23]. Comparing these studies with our study, the majority of Patients were treated by Laparoscopic Appendectomy $86(66.2 \%) .13(10 \%)$ of Patients were treated by Open Appendectomy and Appendectomy Deferred for 31 (23.8\%) of Patients. Follow up was done for all the patients whom appendectomy was deferred to a minimum time period of 6 weeks. No recurrence of symptoms occurred in the postoperative follow up period. 3 patients who were diagnosed to have appendicular mass, had undergone interval appendectomy between a periods of 6-10 weeks.

Hence the sensitivity of our study is $97.1 \%$ when compared to histopathological findings as gold standard. All the 130 patients who were diagnosed clinically as having the case of acute appendicitis would have been subjected to exploration and subsequent appendectomy. Diagnostic laparoscopy in 31 patients (28 having normal looking appendix at laparoscopy and 3 having appendicular mass formation) has led to a decrease in unnecessary operations and its subsequent morbidities. Hence the negative appendectomy which was avoided by doing diagnostic laparoscopy was $\{130-(99+2)\}$. This is equal to 28 . Negative appendectomy rate which would have been $\{31 /$ $130\}^{*} 100=23.846 \%$, which was, after diagnostic laparoscopy reduced to $0 \%$. Hence the specificity of the procedure is equal to 1 as negative appendectomy rate is $0 \%$. All theappendicular specimen was sent for histopathology and was found to be positive for appendicitis.

\section{Conclusion}

Diagnostic laparoscopy is useful as a diagnostic tool in patients with suspected appendicitis, achieving both high sensitivity and specificity rates. It is a semi invasive procedure and should be used in patients with doubt in the diagnosis of appendicitis, as often occurs in females of childbearing age, but could be used as a routine if appendectomy can be performed laparoscopically. Further, diagnostic laparoscopy lowered the negative appendectomy rate from $23.846 \%$ to $0 \%$ without increasing the total number of operations. Women of the reproductive age group benefit most from diagnostic laparoscopy because of its increased validity in other differential diagnoses. 


\section{References}

1. Andren-Sandberg A, Ryska M. Exploratory laparoscopy at suspicion of acute appendicitis. Review. Rozhledy $\mathrm{v}$ chirurgii: mesicnik Ceskoslovenske chirurgicke spolecnosti. 2004; 83(3):131-7.

2. Sazhin VP, Avdovenko AL, Klimov DE, Malashenko PA, Sazhin AV, Iurishchev VA. Possibilities in diagnostic laparoscopy of acute appendicitis. Khirurgiia. 2002; 8:24-7.

3. Moberg AC, Montgomery A. Introducing diagnostic laparoscopy for patients with suspected acute appendicitis. Surgical endoscopy. 2000; 14(10):942-7.

4. Ferris, Mollie BSc, DVM, MD, FRCP; Quan, Samuel B.Sc. ; Kaplan, Belle S. BSc; Molodecky, Natalie MD,The Global Incidence of Appendicitis: A Systematic Review of Population-based Studies: Annals of Surgery. 2017; 266(2):237-241.

5. Berry J, Mall A. Appendicitis near its centenary. Annals of surgery. 1994; 200:567-575.

6. Kotiszo B, Mesele G. Acute appendicitis in Ethiopia. EAMJ. 1996; 73:251-252.

7. Jeffrey RB. Laing FC. Townsend RR. Acute appendicitis: sonographic criteria based on 250 cases. Radiology. 1988; 167(2):327-329.

8. Horton MD, Counter SF, Florence MG, Hart MJ. A prospective trial of Computed Tomography and Ultrasonography for Diagnosing Appendicitis in the Atypical Patient. Am JJ Surg. 179:379-381.

9. Sivit CJ, Applegate KE, Stallion A, Dudgeon DL, Salvator A, Schluchter $\mathrm{M}$ et al. Imaging evaluation of suspected appendicitis in a pediatric population: effectiveness of sonography versus CT. AJRR. 175:977-980

10. Balthazar EJ, Birnbaum BA, Megibow AJ, Roshkow J, Gray C. Acute appendicitis: CT and USS correlation in 100 patients. Radiology. 1994; 190(1):31-35.

11. Kum CK, Sim EKW, Goh PMY, Ngoi SS, Rauff A. Diagnostic laparoscopy: Reducing the Number of Normal Appendectomies. Dis Colon Rectum. 1993; 36:763-766.

12. Jadallah FA, Abdul-Ghani AA, Tibblin S. Diagnostic laparoscopy reduces unnecessary appendectomy in fertile women. Eur J Surg. 1994; 160(1):41-5.

13. Borgstein PJ, Gordijn RV, Eijsbouts QAJ, Cuesta MA. Acute appendictis A clear-cut case in men, a guessing game in young women. Surg. Endosc. 1997; 11:923-927.

14. Tijtgat SHAJ, Bakker XR, Butzelaar RMJM. Laparoscopic evaluation of patients with suspected appendicitis. Surg. Endosc. 1998; 12:918-920.

15. Moberg AC, Ahlberg G, Leijonmarck CE, Montgomery A, Reiertsen O, Rosseland AR et al. Diagnostic laparoscopy in 1043 patients with suspected acute appendicitis. Eur J Surg. 1998; 164(11):833-40, discussion 841.

16. Barrat C, Catheline J-M, Rizk N, Champault GG. Does laparoscopy reduce the incidence of unnecessary appendectomies? Surg. Laparosc. \& Endosc. 9:27-31.

17. Van den Broek WT, Bijnen AB, Van Eerten PV, De Ruiter $\mathrm{P}$, Gouma DJ. Selective use of diagnostic laparoscopy in patients with suspected appendicitis. Surg Endosc. 2000; 14:938-941.

18. Wang Y, Reen DJ, Puri P. Is a histologically normal appendix following emergency appendicectomy always normal? The Lancet. 1996; 347:1076-1079.

19. Semm K, Mettler L. Progress in pelvic surgery via operative laparoscopy. Am J Obstet Gynecol. 1980; 138:121-127.

20. McCall JL, Sharpies K, Jadallah F. Systematic review of randomized controlled trials comparing laparoscopic with open appendectomy. Br J Surg. 1997; 84:1045-1050.

21. Garbutt JM, Soper NJ, Shannon WD, Botero AB, Littenberg B. Meta-analysis of Randomized Controlled Trials Comparing Laparoscopic and Open Appendectomy. Surg. Laparoscopy \& Endosc. 1999; 9:17-26.

22. Golub R, Siddiqui F, Pohl D. Laparoscopic versus open appendectomy: a meta-analysis. J Am Coll Surg. 1998; 186:545-553.

23. Sauerland S, Lefering R, Holthausen U, Neugebauer EAM. Laparoscopic vs conventional Appendectomy-a metaanalysis of randomized controlled trials. Langenbeck's Arch. Surg. 1998; 383:289-2955. 